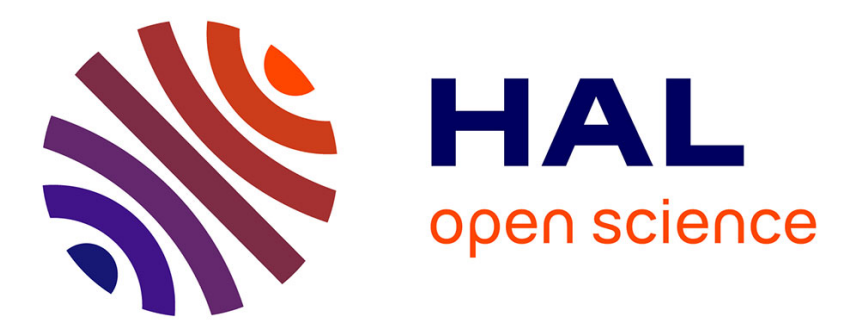

\title{
Drop-on-demand extraction from a water meniscus by a high field pulse
}

Pierre Atten, A. Ouiguini, Jonathan Raisin, Jean-Luc Reboud

\section{To cite this version:}

Pierre Atten, A. Ouiguini, Jonathan Raisin, Jean-Luc Reboud. Drop-on-demand extraction from a water meniscus by a high field pulse. International Conference on Dielectric Liquids (ICDL-2008), Jun 2008, Poitiers, France. hal-00372095

\section{HAL Id: hal-00372095 \\ https://hal.science/hal-00372095}

Submitted on 31 Mar 2009

HAL is a multi-disciplinary open access archive for the deposit and dissemination of scientific research documents, whether they are published or not. The documents may come from teaching and research institutions in France or abroad, or from public or private research centers.
L'archive ouverte pluridisciplinaire HAL, est destinée au dépôt et à la diffusion de documents scientifiques de niveau recherche, publiés ou non, émanant des établissements d'enseignement et de recherche français ou étrangers, des laboratoires publics ou privés. 


\title{
Drop-on-demand Extraction from a Water Meniscus by a High Field Pulse
}

\author{
P. Atten, A. Ouiguini, J. Raisin and J.-L. Reboud \\ G2Elab, CNRS, Univ. Joseph Fourier and INP Grenoble, \\ BP 166, 38042 Grenoble Cedex 9, France
}

\begin{abstract}
As a part of a study of electrocoalescence of water droplets in oil, the controlled generation of small drops (diameter $\sim 100 \mu \mathrm{m}$ ) is considered. The technique used consists in applying a voltage pulse promoting the deformation of a meniscus at the end of a capillary tube through the action of electric forces. For pulses of short enough duration, the transient deformation can lead to the ejection of a small drop electrically neutral.

The experimental results of water drops extraction in oil are presented. Using capillary tubes of outer tip diameter varying from $0.5 \mathrm{~mm}$ to $1 \mathrm{~mm}$, it is possible to obtain in a reproducible way drops of diameter ranging from $50 \mu \mathrm{m}$ to $200 \mu \mathrm{m}$. For a given meniscus shape, the diameter of the extracted droplet depends on the voltage amplitude $V$ and on the pulse duration $\Delta t$. Order of magnitude considerations on the meniscus deformation process suggest that the main parameter which determines the size of the generated droplet is the product $V^{2} \Delta t$. The experimental results support this guess for pulse durations low enough so that there is no electrical field (and, therefore, no surface charge) during the last stage of meniscus elongation and break-up. The possible use of this technique of drop-on-demand generation is discussed, taking into account the transient oil flow around the meniscus which most often brings the droplet off the system axis.
\end{abstract}

\section{INTRODUCTION}

Electrocoalescence is the phenomenon of coalescence of droplets, suspended in an insulating liquid or a gas, under the action of an electric field. In the petroleum industry, electrocoalescence has been used for over 100 years in oil treatment: elimination of suspended particles, salts, water and some compounds from the crude oil. The introduction of this technique allowed considerable gains in terms of productivity as electrocoalescence is used to increase the size of suspended water droplets, which results in a dramatic decrease of the time required for gravitational sedimentation $[1,2,3]$. In recent compact electrocoalescers, the water in oil emulsion flows between two coaxial electrodes [4]. In these devices, coalescence of water droplets occurs in two different phases: first, there is a build-up of drop pairs by the fluid shear flow bringing some droplets in close proximity; in a second stage, the coalescence itself is promoted by the field induced attraction, deformation and break-up of their interfaces [5]. The basic phenomenon has been described in many previous papers [5-8]. Nevertheless usable criteria to predict the coalescence of two water droplets in crude oil, under the effect of a given electric field, should still be formulated and widely validated. Establishing such criteria remains quite difficult, as it involves many parameters (fluids densities and viscosities, surface tension, flow velocity and shear, presence of particles and chemical species ...).

To identify the governing parameters, we intend to carry out an experimental study of the electrocoalescence of two water droplets in an oil shear flow. It will consist in injecting electrically neutral drop pairs of controlled volume at given locations in an oil shear flow, and in analyzing their coalescence under varying electric fields. A crucial requirement for this study is to generate water droplets in a controlled way and we examine here a technique based on pulsed electric field applied to a water-oil meniscus.

\section{PRINCIPLE OF DROP EJECTION}

\section{A. Background}

The ability of electric forces to draw liquid from surfaces has been known for many years but its application to liquid ejection is more recent. Devices such as ink printers were for example mainly based on the use of pressure pulses [9]. With pressure ejection, the drop size is closely tied to the orifice size, so that drops of a few microliters would require small capillaries and orifices, difficult to manufacture and prone to clogging. Electric spraying, on the other hand, can produce a wide range of drop sizes, including drops much smaller than the orifice.

Electrohydrodynamic (EHD) spraying has been the subject of many papers in recent years $[10,11]$ and many techniques have been developed that can basically be classified in two categories [9]: those based on cone-jet mode, and those based on "drop periodic". Cone-jet refers to the conical or tapering meniscus with the fine jet issuing from the tip and is not ideal for droplet generation. "Drop periodic" means any mode in which drops are pulled one by one such as dripping and spindle mode $[11,12]$. All these techniques produce charged droplets that are not suitable for tests on water in oil electrocoalescence.

Reference [13] presents a recent method for non-charged droplets generation. It relies on the use of a co-flowing outer fluid that pulls a liquid drop formed at the tip of a tube. However, drops of a few micro liters can not be obtained without the apparition of a jet.

In 1993, Wright et al. [9], have considered using voltage pulse in addition to pressure pulse to generate single droplets. They developed a numerical model simulating droplet ejection. They showed that applying only a voltage pulse can result in a drop ejection. We focus here on this particular mechanism of drop ejection and present results of an experimental study. 


\section{B. Surface deformation, elongation and break-up}

The injection of a single and non charged water droplet in oil is obtained by applying a voltage pulse on a conductive liquid meniscus that will deform and finally break-up. The major difference with the work of Wright et al. [9,14] is that the only pressure acting on the meniscus is the electrostatic pressure $P_{e s}=1 / 2 \& E_{n}{ }^{2}$, where $E_{n}$ is the normal component of the electric field and $\varepsilon$ is the oil permittivity. We apply a voltage pulse defined by a temporal shape, as square as possible (to reduce lead and trail times), an amplitude and a duration.

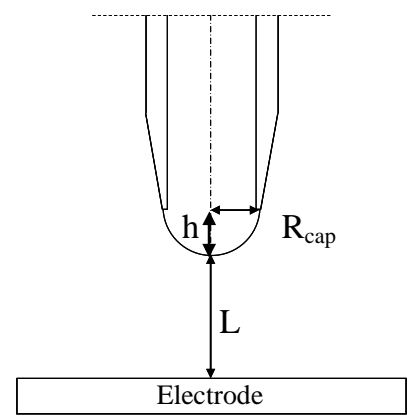

Fig. 1. Main geometrical parameters of a meniscus involved in critical field estimation.

Concerning the pulse amplitude $V$, a lower bound can be defined by the balance on the meniscus surface of electrostatic pressure $P_{e s}$ and capillary pressure $P_{c a p}$ :

$$
P_{e s}=P_{c a p} \Rightarrow \frac{1}{2} \varepsilon E_{n}^{2}=\frac{2 T}{R_{c a p}}
$$

where $T$ is the interfacial tension coefficient and $R_{c a p}$ is the meniscus radius of curvature. The instability that causes break-up and drop ejection appears in the highest field region located, in the configuration described on Fig. 1, on the axis at the tip of the meniscus. An approximation of the maximum field intensity, calculated for a hyperbolical surface having the same radius of curvature, is given by:

$$
E_{\text {max }}=\frac{2 V}{R_{c a p} \log \left(\frac{4 L}{R_{c a p}}\right)}
$$

where $L$ is the distance between the meniscus and the electrode. The typical voltage can then be calculated by replacing $E$ in (1) by $E_{\max }$. With the typical values $R_{\text {cap }}=0.4$ $\mathrm{mm}, L=2 \mathrm{~cm}, \varepsilon=210^{-11} \mathrm{~F} / \mathrm{m}$ and $T=25 \mathrm{mN} / \mathrm{m}$, one obtains $V=3750 \mathrm{~V}$.

Concerning the pulse duration, the ejecting of an electrically neutral drop implies that electric pulse is finished before the last stage of meniscus elongation and break up, i.e. the appearance of a liquid filament between the drop and the meniscus. Pulse duration $\Delta t$ should be less than the characteristic capillary time $t_{c a p}[14]$ :

$$
t_{\text {cap }}=\sqrt{\frac{\rho R_{\text {cap }}^{3}}{T}}
$$

where $\rho$ is the density of the liquid flowing in the capillary (here water). Typically $t_{\text {cap }} \sim 1.6 \mathrm{~ms}$

\section{EXPERIMENTAL SETUP AND PROCEDURES}

\section{A. Experimental Setup}

A cell for injection tests has been designed (Fig. 2) and built: it is a cube made of PVC and Plexiglas to allow visualization in two directions. It includes a ten microliters syringe mounted on a metallic needle and a circular electrode fixed at the bottom. A water meniscus is formed manually at the tip of the needle, electrically grounded, and high voltage is provided to the electrode during the ejection process. The cell is filled with synthetic oil (polybutene). Injected droplets are collected in a small hole at the top of the electrode. The distance between the electrode and the meniscus can be adjusted.

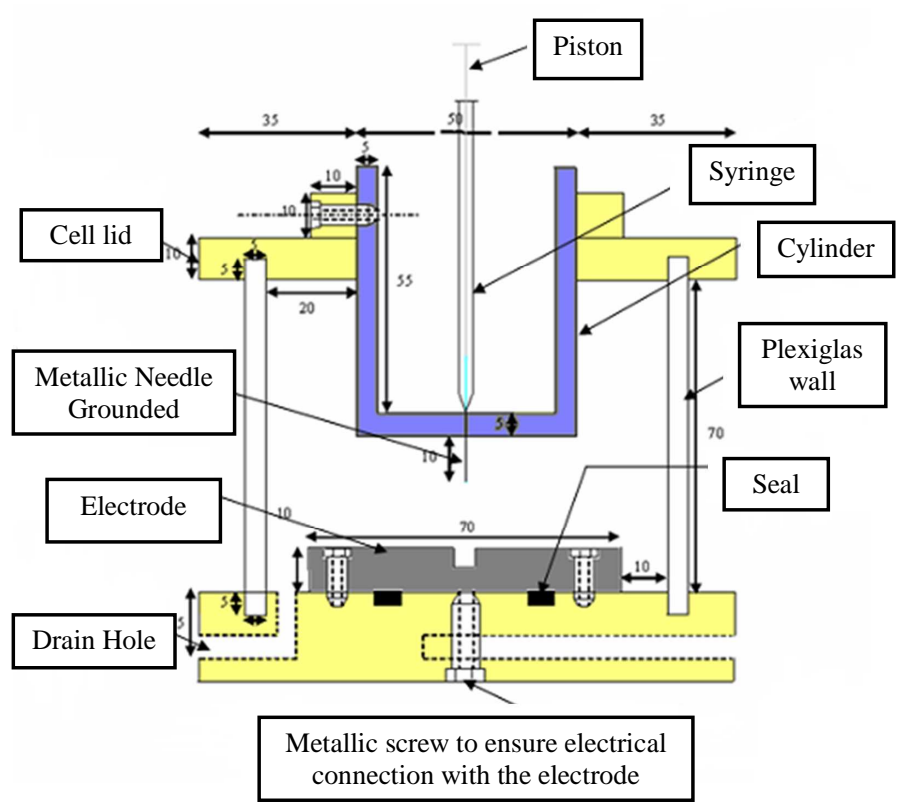

Fig. 2. Injection cell

Figure 3 presents the experimental setup. The electric circuit is composed of a High Voltage Pulse Source, a $1 \mathrm{M} \Omega$ resistance and the cell placed in series. Pulses are created by an arbitrary wave generator and multiplied (x2000) by a TREK high voltage amplifier. An oscilloscope is used to control the pulse shape. The setup also includes two cameras: the first one is a CCD camera linked to a computer and is used to take screenshots and visualize meniscus and injected droplets with high magnification; the second camera linked to a monitor is used to estimate the fall velocity of injected droplets. 


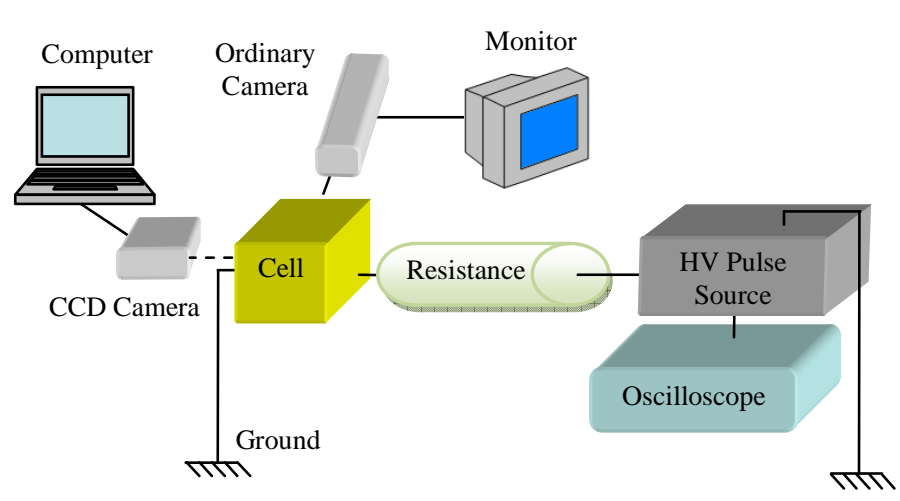

Fig. 3. Experimental setup

\section{B. Tests and methods for estimation of drop diameter}

Preliminary tests have been conducted on the influence of the needles shape. An important parameter of the injection is the anchorage of the water meniscus on the needle: it has been noticed during injection with usual needles that the anchorage point was moving from the inner diameter to the outer diameter resulting in non-reproducible drop ejections. This problem is avoided by reducing the needle thickness or simply by using conical needles, as illustrated in Fig. 1.

Two methods have been considered to evaluate drop diameter: one consists in timing the fall of one drop between two marks positioned, on a monitor, according to an order of magnitude calculation in order to have a fall at a constant velocity. Diameter is then inferred by replacing this velocity in Stokes' formula:

$$
V_{\text {ter }}=\frac{1}{3} \frac{\Delta \rho g R_{d}^{2}}{\eta}
$$

where $\Delta \rho$ is the density difference between the drop and the surrounding liquid (here water and oil), $g$ is the gravitational acceleration, $\eta$ is the dynamic viscosity of the surrounding liquid and $R_{d}$ is the drop radius. The second method relies on image analysis: a screenshot of an injected droplet is taken (Fig. 4) and, assuming that the diameter of the capillary is known, drop diameter is deduced from the ratio between the respective numbers of pixels on the image.

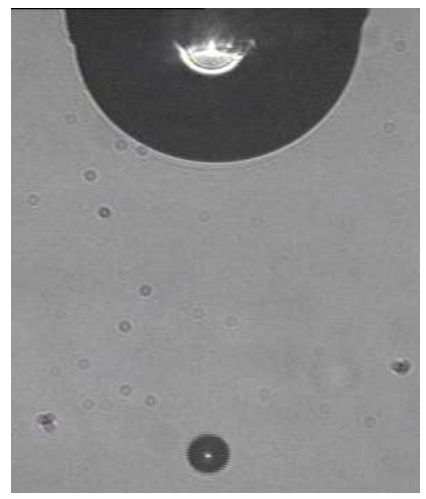

Fig. 4. Injected droplet and water meniscus
Reproducibility tests have been performed to evaluate the strengths and weaknesses of both methods. Image analysis offers more consistent results as it has no time dependent source of errors (especially natural convection due to gradient of temperature) and was chosen for further measurements. However, as trajectory of the just ejected drop exhibits a random behavior (non axial), the optical focus is sometimes bad and so the accuracy of the results can still be improved.

\section{RESULTS AND DISCUSSION}

The measurements have been carried out with two conical needles of different diameters $(0.66 \mathrm{~mm}$ and $0.557 \mathrm{~mm})$. For each needle, two different shapes of meniscus have been used $\left(h=R_{\text {cap }}\right.$ and $h=3 / 4 R_{\text {cap }}$ ). Figs. 5 and 6 represent the diameter of ejected droplets as a function of the square of the applied voltage pulse for different pulse durations (each point is the average of 7 to 10 measured values). As the trends observed with both needles are identical, only the results obtained with the needle of $0.66 \mathrm{~mm}$ diameter are presented.

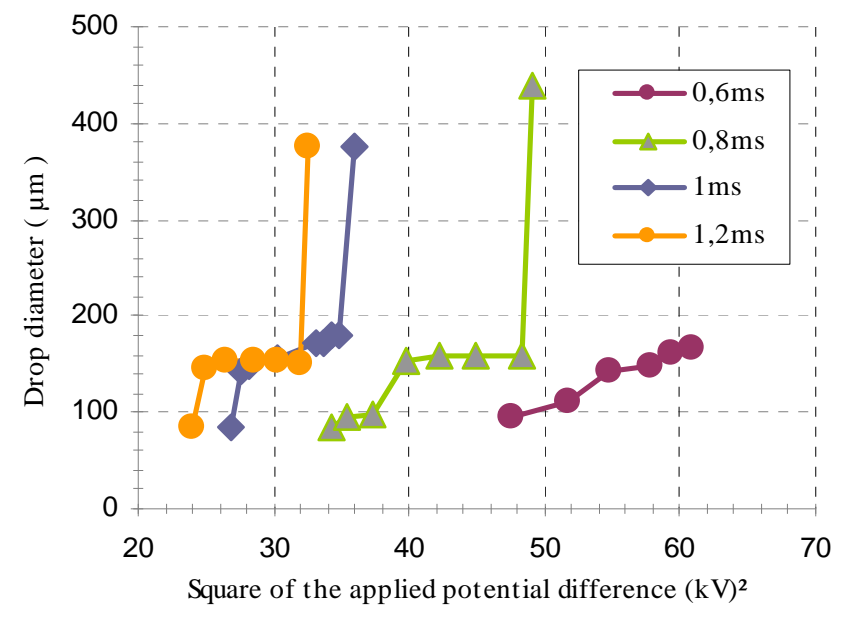

Fig. 5. Variation of the diameter of injected droplets as a function of the square of the voltage pulse amplitude, $h=R_{c a p}$

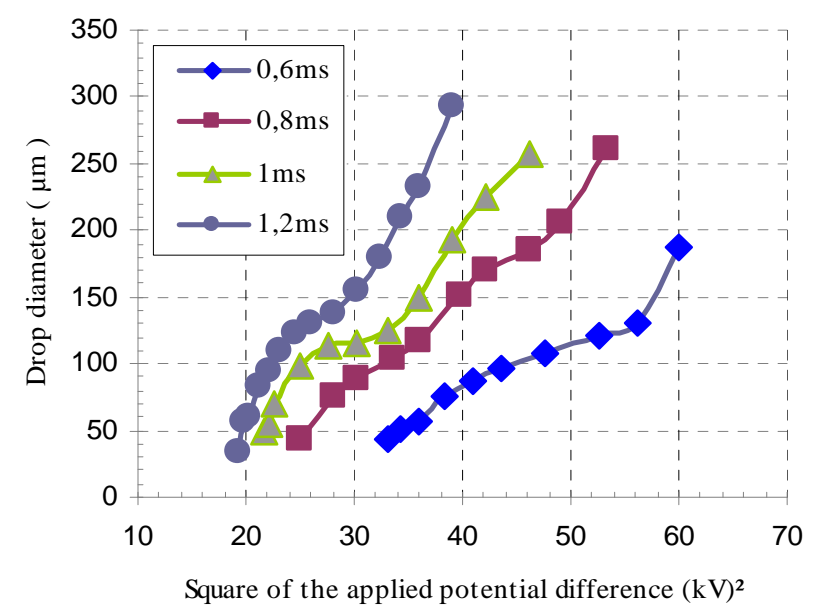

Fig. 6. Variation of the diameter of injected droplets as a function of the square of the voltage pulse amplitude, $h=3 / 4 R_{c a p}$ 
For a meniscus defined by $h=R_{\text {cap }}$ (Fig. 5), the results of ejected drop diameter can be divided into three distinct parts: i) in the first one, drop diameters rise progressively as the pulse amplitude $V$ is increased; ii) in the second part, all the curves present a plateau and the pulse amplitude has very low influence on ejected drop diameter; iii) in the last part, drop diameter grows abruptly, making it hard to control. For a meniscus defined by $h=3 / 4 R_{\text {cap }}$ (Fig. 6), there is a much smoother variation of drop diameter with voltage amplitude, without any plateau or jump.

In order to explain these differences, the ejection mechanism has to be investigated: as previously mentioned, two key parameters control the pulse (duration and amplitude). They are linked by the work of the electrostatic force $W_{e} \sim S$ $P_{e s} \Delta t$ where $S$ is the surface of the meniscus. As the meniscus deforms, the radius of curvature and the active area decrease, but this decrease is compensated for by the increase of $E_{n}$ (see (2)). To a rough approximation we obtain for the work $W_{e}$ :

$$
W_{e} \sim \frac{\pi}{2} \frac{\varepsilon V^{2} \Delta t}{\log ^{2}\left(4 h / R_{c a p}\right)}
$$

Equation (5) shows that the product $V^{2} \Delta t$ is the lead term of the work of the electrostatic force as the influence of the meniscus radius is lowered by the logarithm. This is confirmed by plotting graphs representing the variation of drop diameter as a function of $V^{2} \Delta t$ (Fig.7.).

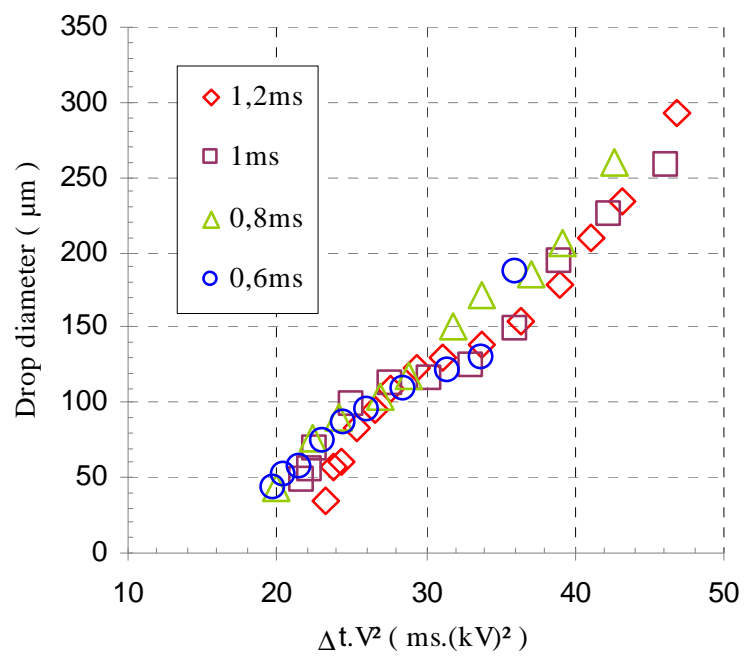

Fig. 7. Variation of the diameter of injected droplets as a function of the product $\Delta t . V^{2}, h=3 / 4 R_{c a p}$

Fig.7. shows that in the case of a meniscus defined by $h=3 / 4$ $R_{\text {cap }}$, the phenomenon of drop injection is well-defined and that a wide range of diameter can easily be obtained by adjusting the pulse parameters. For a meniscus defined by $h=$ $R_{\text {cap }}$, this kind of graph shows two spaced bunch of points: one representing the two first step of the phenomenon of drop injection and one representing the jump. This indicates an important change in the mechanism of injection (most likely the injection of a charged droplet).

\section{CONCLUSION}

The key parameters of the high field pulse based injection of water droplets in oil have been identified as pulse duration $\Delta t$ and amplitude $V$. A preferred shape of meniscus has been highlighted and it is now possible to inject, in a reproducible way, drops with a wide range of diameter (between $40 \mu \mathrm{m}$ and $250 \mu \mathrm{m}$ which is much smaller than the capillary diameter). Future work should focus on injection trajectory, randomly non axial, probably due to flow disturbances in the oil.

\section{ACKNOWLEDGMENT}

This work is developed in the framework of a collaborative research between the French CNRS and the Consortium working on the project "Electrocoalescence - Criteria for an efficient process in real crude oil systems"; co-ordinated by SINTEF Energy Research. Contact person is L.E. Lundgaard. The project is supported by The Research Council of Norway, under the contract no: 169466/S30, and by the following industrial partners: Vetco Aibel AS, Aker Kvaerner Process Systems AS, StatoilHydro ASA, BP Exploration Operating Company Ltd, Shell Technology Norway AS, Petrobras.

\section{REFERENCES}

[1] L.C. Waterman, "Electrical coalescers", Chemical Engineering Progress, 61 (10), 1965, pp. 51-57.

[2] J.S. Eow, M. Ghadiri, A.O. Sharif, T. Williams, "Electrostatic enhancement of coalescence of water droplets in oil: a review of the current understanding", Chem. Eng. J., 84 (3), 2001, pp. 173-192.

[3] J.S. Eow, M. Ghadiri, "Electrostatic enhancement of coalescence of water droplets in oil: a review of the technology", Chem. Eng. J., 85, 2002, pp. 357-368.

[4] O. Urdahl, N.J. Wayth, H. Førdedal, T.J. Williams and G. Bailey, "Compact Electrostatic Coalescer Technology", Encyclopedic handbook of emulsion technology, J. Sjöblom, Ed. CRC, pp. 549-592.

[5] P. Atten, L.E. Lundgaard and G. Berg, "A simplified model of electrocoalescence of two close water droplets in oil", $J$. of Electrostatics, vol. 64, pp. 550-554, 2006.

[6] P. Atten and F. Aitken, "On the basic mechanism of electrocoalescence", Proceedings of the ESA/IEEE-IAS/IEJ/SFE Joint Conference on Electrostatics, ISBN 1-885540-18-3, pp. 45-54, 2006.

[7] L.E. Lundgaard, G. Berg, S. Ingebrigtsen and P. Atten, 2006, "Electrocoalescence for oil-water separation: Fundamental aspects", in Emulsions and emulsion stability, J. Sjöblom, Ed. CRC Press, Taylor \& Francis, pp. 549-592.

[8] J.A. Melheim and M. Chiesa, "Simulation of turbulent electrocoalescence", Chem. Eng. Science, 61, 2006, pp. 4540-4549.

[9] G.S. Wright, P.T. Krein and J. Chato, "Self-Consistent Modeling of the Electrohydrodynamics of a conductive Meniscus", Conf. Rec. 1993 IEEE-IAS Annual Meeting, 93CH3366-2, pp. 1946-1955.

[10] M. Cloupeau and B. Prunet-Foch, "Electrostatic spraying of liquids: main functioning modes", J. of Electrostatics, vol. 25, pp. 165-184, 1990.

[11] A. Jarowek and A. Kruppa, "Jet and drop formation in electrohydrodynamic spraying of liquids. A systematic approach", Experiments in Fluids, vol. 27, pp. 43-52, 1999.

[12] J.M. Grace and J.C.M. Marijnissen, "A review of liquid atomization by electrical means", J. of Aerosol Science, vol. 25, pp.1005-1019, 1994.

[13] R. Suryo and O.A. Basaran, "Tip streaming from a liquid drop forming from a tube in a co-flowing outer fluid", Phys. Fluids, vol. 18, 2006.

[14] G.S. Wright, P.T. Krein and J. Chato, "Factors affecting dynamic electrical manipulation of menisci", IEEE Transactions on Industry Applications, vol. 29, no. 1, pp 103-112, Jan./Feb. 1993. 